\title{
Faz değişim malzemeli ısı değiştirici üzerine parametrik bir çalışma
}

\author{
Mustafa Asker $^{1 *}$, Hüseyin Günerhan ${ }^{2}$ \\ ${ }^{1}$ Adnan Menderes Üniversitesi, Mühendislik Fakültesi, Makina Mühendisliği Bölümü, Merkez Kampüs, Aytepe Mevkii, Aydın, 09010, Türkiye \\ ${ }^{2}$ Ege Üniversitesi Mühendislik Fakültesi Makina Mühendisliği Bölümü Bornova, İzmir, 35040, Türkiye
}

Ö N E Ç I K A N L A R

- $\quad$ Faz değişim malzemeli soğutucunun 1sıl tasarımının gerçekleştirilmesi

- Isı değiştiricisi içerisindeki boru dizilişlerinin toplam ergime zamanına olan etkisi

- $\quad$ Fan gücü ve borular arasındaki mesafenin 1sı değiştirici performansına olan etkileri

Makale Bilgileri

Geliş: 06.06.2013

Kabul: 04.05.2016

DOI:

10.17341/gummfd.76037

Anahtar Kelimeler:

Faz değişim malzemeleri, 1s1 değiştirici,

ergime zamanı

\section{ÖZET}

$\mathrm{Bu}$ çalışmada, boruları düşey konumda olan gövde boru tipi bir 1sı değiştiricide, borular içinde $23^{\circ} \mathrm{C}$ sıcaklıkta ergiyebilen faz değişim malzemesi bulunan bir sistem ele alınmıştır. Isı transfer akışkanı olan hava sisteme fan aracılığıyla sağlanmıştır. Bu çalışmada öncelikle faz değişim malzemeli 1sı değiştiricinin tasarımına ilişkin sayısal bir yöntem geliştirilmiş ve elde edilen sonuçlar daha önce yapılan analitik yöntemin sonuçları ile karşılaştırılmıştır. Daha sonra, faz değişim malzemeli 1sı değiştiricinin hacmi sabit tutulmuş ve sistem üzerinde parametrik bir çalışma yapılmıştır. Boru aralığı değişimi, hava debisi (fan hızı) değişimi ve faz değişim malzemesi değişken parametreler olarak ele alınmıştır. Boru sayısı akışa dik yönde iki kat arttığında toplam ergime zamanı tüm dört aralık durumu için ortalama olarak \%38 oranında azalmıştır.

\section{Parametric study of phase change material heat exchanger}

\section{H I G H L I G H T S}

- Thermal design of phase change material cooler

- Investigation of the effect of tube pitch on total melting time

- Investigation of the effect of fan power and tube pitch on the performance of the heat exchanger

Article Info

Received: 06.06.2013

Accepted: 04.05.2016

DOI

10.17341/gummfd.76037

Keywords:

Phase change material,

heat exchanger,

melting time

\section{GİRİS (INTRODUCTION)}

Dünyada yaşanan iklim değişikliğinin sonucunda, kış mevsiminde olan 1sıtma ihtiyacının yanında yaz şartlarında sağlanan soğutma ihtiyacında da artış görülmüştür. Soğutma işleminde daha çok enerji harcandığından dolayı, istenen konfor koşullarının sağlanması için çevreye duyarlı ekonomik çözümlere yönelinmesi gerekmektedir. Birim miktarda depolanan enerji başına daha az hacim

\begin{abstract}
In this work a phase change material unit which consist of shell and tube heat exchanger in which tubes are vertical and filled with a phase change material that melts at $23^{\circ} \mathrm{C}$ is used. First a numerical method for the design of phase change material cooler is presented then a numerical solution is obtained and compared with results of published analytical solution. The volume of phase change material heat exchanger is taken constant and a parametric study such as tube pitch, fans speed and phase change material is made. For all four cases of tube arrangement, it is found that as the tube pitch doubled in the direction of the flow, the total melting time decreased about $38 \%$.
\end{abstract}

gerektirmesi ve faz değişimli 1sı geçişi sırasında meydana gelen dar sıcaklık aralığı nedeniyle, gizli enerji depolama sistemleri, faz değişimli sistemler, birçok araştırmacının ilgisini çekmiş ve bu konu üzerinde birçok çalışma yapılmıştır [1-6]. Isıl enerji depolama teknikleri 1sıtma ve soğutma sistemlerinde, enerjinin daha etkin ve verimli kullanımını sağlayarak toplam enerji maliyetinde önemli ölçüde tasarruf sağlamaktadır. Bu durum fosil yakıtların daha az kullanımına neden olmakta ve çevre ile dost

\footnotetext{
* Sorumlu Yazar/Corresponding author: mustafa.asker@adu.edu.tr / Tel: 02562137503
} 
iklimlendirme teknikleri geliştirme olanağını sunmaktadır [7-9]. Yerel yenilenebilir enerji kaynaklarının, isıl enerji depolama işlemi uygulanması ile birlikte kullanımı sonucunda verimli sistemler tasarlanabilir $[10,11]$. Faz değişim malzemeli taşınabilir soğutucular üzerine yapılmış çalışmalar incelendiğinde, Dietz [12] tarafından bir dikdörtgen 1S1 depolama modelinin geliştirildiği görülmüştür. Geliştirilen modelin içerisine belirli bir düzende düşey konumda silindirik depolayıcılar yerleştirmiştir. Faz değişim malzemesi olarak kalsiyum klorür hekzahidrat kullanılmıştır. Isı transfer akışkanı olan hava ise boruların arasından geçirilmiştir. Faz değişim malzemesinin şarj ve deşarjı sırasında elde edilen deneysel sonuçlara göre, sistemin ısıl performansını sağlayacak basit bir matematiksel model geliştirilmiştir. Farid ve Kanzawa [13] tarafından gövde-boru tipi 1S1 değiştiricisi olarak tasarlanan bir 1sıl depolama ünitesi incelediğinde boruların faz değişim malzemesi ile doldurulmuş olduğu ve hava akışının boruların etrafındaki gövde içinden sağlandığı görülmüsstür. Yapılan benzetim, aynı ünitede ergime sıcaklıkları farklı olan farklı faz değişim malzemelerinin kullanılması ile ünitenin etkinliğinin arttırılabileceğini göstermiştir. Lacroix [14] faz değişim malzemesinin gövde içinde depolandığ 1 ve düşey borular içerisinden 1sı transfer akışkanının geçtiği gövde-boru tipi 1sı değiştiricili bir üniteyi incelemiştir. Ünite sayısal olarak benzetim yöntemleri ile incelenmiş ve modelin doğruluğunu göstermek için deneysel çalışmalar gerçekleștirilmiștir. Esen ve Ayhan [15] tarafindan güneş enerjili 1sı depolama sisteminde, faz değiștiren madde içeren bir silindirik tank deposunun performansı deneysel olarak incelenmiştir. $\mathrm{Bu}$ çalışma kapsamında tank içinde belirli sayıda silindirler dikey olarak yerleştirilmiş, silindirler faz değişim malzemeleri ile doldurulmuş ve 1 sı transfer akışkanı buna paralel olarak akıtılmıştır. Faz değişim malzemesi olarak kalsiyum klorür hekzahidrat $\left(\mathrm{CaCl}_{2} \cdot 6 \mathrm{H}_{2} \mathrm{O}\right)$, parafin mumu $\left(\mathrm{Na}_{2} \mathrm{SO}_{4} \cdot 10 \mathrm{H}_{2} \mathrm{O}\right)$ ve parafin kullanılmıştır. Farklı 1sı transfer akışkanlarının debisi ve giriş sıcaklığ 1 ve farklı faz değişim malzemesi için ergime davranışının değişimi sayısal olarak entalpi yöntemi ile belirlenmiştir. Turnpenny vd. [16, 17] ise bir 1S1 borusunun faz değişim malzemesi içerisine yerleştirildiği bir ünite üzerinde çalışmışlardır. Bu üniteden binaların havalandırma soğutma işleminde yararlanılmıștır. Vakilaltojjar ve Saman [18] 1sıl enerji depolama ünitesini sayısal olarak incelemişlerdir. Depolama ünitesi yatay dikdörtgen kesitli ve belirli sayıda tabakalardan oluşan faz değişim malzemesi ile doldurulmuştur. Isı transfer akışkanı (ortam havası) ise tabakalar arasında boşlukların üzerinden akıtılmıștır. Matematiksel modelde doğal taşınımın etkisi göz önüne alınarak entalpi metodu ile sonlu farklar yöntemi kullanılarak elde edilmiştir. Hava giriş sıcaklığ 1 ve hava debisi gibi 1sıl performans özelliklerinin 1s1 transfer oranı ve ergime zamanı üzerine etkisi gösterilmiştir. Mozhevelov [19] yaptığı bir çalışmada, gerçek ölçülerdeki bir odada taşınabilir bir soğutucuda soğutucu elemanlarının gövde içinde farklı şekilleri için (düşey plakalar, yatay plakalar, yatay kare kesitli borular düzgün sıralı ve şaşırtılmış sıralamalı yerleşimlerde) üç boyutlu ve zamana bağlı benzetimleri gerçekleştirmiştir. Mozhevelov vd. [20] ise bir odanın duvarlarına paralel olarak yerleştirilmiş düşey ince depolama üniteleri üzerinde çalışmışlardır. Mevcut isı gün içinde odadan doğal taşınım ile çekilmiş ve faz değişim malzemesi eritilmiştir. Gece şartlarında ise doğal ve zorlanmış taşınım ile 1s1 üniteden çevreye atılmış ve faz değişim malzemesi dönüştürülmüsştür. Arye ve Guedj [21] boruları düşey konumda ve içleri faz değişim malzemesi ile dolu olan bir gövde-boru tipi 1S1 değiştiricili ünite ile deneyler gerçekleştirmişlerdir. Oda havası fanlar kullanılarak gövde içine zorlanmış taşınım ile gönderilmiştir. Faz değişim malzemesi olarak, çevre sıcaklığı gündüz $30-35^{\circ} \mathrm{C}$ aralı̆̆ında, gece ise $18-19^{\circ} \mathrm{C}$ civarlarında iken $22-24^{\circ} \mathrm{C}$ sicaklıklarında eriyen parafin kullanılmıştır. Faz değişim malzemesi gündüz eriyip gece katılaşmış, böylece odada isıl konfor sağlanmıştır. Kozak vd. [22] faz değişim malzemesinden ve havadan oluşan bir hibrit 1S1 değiştirici üzerinde sayısal ve deneysel çalışmalarda bulunmuşlardır. Oluşturulan sayısal modelde entalpi yöntemi kullanılmıştır. Sayısal ve deneysel sonuçların belli bir uyum içerisinde olduğu gözlemlenmiştir. Letan ve Ziskind [23] ise taşınabilir bir faz değişimli soğutucunun 1 sıl tasarımı üzerine sayısal bir çalışma yapmışlardır. Dubovsky vd. [24] ise gövde boru tipli bir 1sı değiştiricide kullanılan faz değişim malzemeli soğutucunun analitik çözümü üzerinde çalışmışlardır. Başka bir çalışmada ise Ref. [24]'deki faz değişim malzemeli soğutucu modeli ele alınmış ancak farklı faz değişim malzemesi kullanılmıştır [25]. Bu çalışmada soğutucu olarak gövde boru tipi bir 1sı değiştiricisi ele alınmıştır. Isı değiștiricisi içindeki borular dikey konumdadır ve faz değişim malzemesi ile doldurulmuştur. Ortamın sicak havası fanlar aracılığı ile soğutucuya yönlendirilmektedir. Borular etrafindan geçen sıcak hava borular içinde bulunan faz değişim malzemesini eritmekte ve böylece hava soğuyarak 1S1 değiştiriciden dış ortama atılmaktadır. İncelenen literatür çalışmalarında, analitik çözüm yöntemleri kullanılarak sonuç elde edilmeye çalışıldığı görülmüştür. Bunun yanında boru aralıklarındaki mesafe ve fan gücünün çalışma parametrelerine olan etkisinin yeterli derecede incelenmediği tespit edilmiştir. Bu çalışmada ise literatür çalışmalarına ek olarak faz değișim malzemeli is1 değiştiricide boru dizilişinin toplam ergime zamanı üzerine etkisi irdelenmiştir. Ayrıca fan gücü ve 1S1 değiștiricinin performans değerlendirmesi üzerine hesaplamalar yapılmıştır.

\section{SISTEMIN TANITILMASI VE TASARIM PARAMETRELERI (DEFINITION OF THE PROBLEM AND DESIGN PARAMETERS)}

Bu çalışmada ele alınan soğutucu, çapraz akışlı gövde-boru tipi bir 1s1 değiştiricidir. Boruların içine yerleştirilen faz değişim malzemesi birbirine karışmamakta iken boruların etrafinda dolaşan hava ise karışmaktadır. Soğutucunun dıştan dışa ölçüleri $H=0,8 \mathrm{~m}$ yükseklik, $W=0,21 \mathrm{~m}$ genişlik ve $l=1,35 \mathrm{~m}$ uzunluk olacak şekilde belirlenmiștir [23]. Soğutucu sistemde fanlar düşey olarak yerleştirilmiștir. Havanın serbest akıs hızı borular etrafında $1,4 \mathrm{~m} / \mathrm{s}$ değerinde olacak şekilde belirlenmiştir. Is1 
değiştiricinin genel yapısı Şekil 1'de verilmiştir. Sistemde kullanılan borular dairesel kesitlidir ve alüminyum malzemeden imal edilmiştir. Burada borular düzgün sıralı olarak yerleştirilmiş olup, borular arası mesafe akış yönünde ve akışa dik yönde sırasıyla $S_{p}$ ve $S_{n}$ ile gösterilmiştir. Düşey olarak yerleştirilen boruların dış çapı $D_{d l s}=0,012 \mathrm{~m}$, iç çapı $D_{i c}=0,01 \mathrm{~m}$ ve yüksekliği $H_{b}=0,8 \mathrm{~m}$ olarak belirlenmiştir. Isı değiştiricisinin boyutları akışa dik ve akışa paralel yöndeki toplam boru sayıları $N_{n}$ ve $N_{p}$ olarak gösterilmiştir. Faz değişim malzemesi olarak parafin seçilmiştir [23]. Taşınabilir ölçülerde bir soğutucuya ait 1s1 değiştiricisinin tasarımında izlenmesi gereken 1sıl hesaplamalar aşağıdaki gibi verilmiştir. Faz değişim malzemesinin toplam kütlesi Eş. 1 ile ifade edilmiştir.

$m_{F D M}=N \times V_{b} \times \rho_{F D M}=N\left[\frac{\pi D_{b}^{2}}{4} H_{b}\right] \rho_{F D M}$

Faz değişim malzemesi ve hava arasında gerçekleşen 1s1 transferine ait toplam 1sı transfer yüzey alanı, (Eş. 2), boruların yüzey alanları toplamıdır.

$$
A=N\left(\pi D_{b}\right) H_{b}
$$

Havanın fanlardan borulara doğru aktığı kesit alanı Eş. 3 ile verilmiştir.

$$
A_{k}=W H
$$

Havanın bu kesit alanındaki kütlesel debisi Eş. 4 ile hesaplanmıştır.

$$
\dot{m}_{\text {hava }}=v_{0} \rho_{\text {hava }} A_{k}
$$

Havanın ısıl kapasitesi ise Eş. 5 ile hesaplanmıştır.

$$
\dot{C}_{\text {hava }}=\dot{m}_{\text {hava }} \times c_{\text {p,hava }}
$$

Hesaplamalardan elde edilen sabit parametrelerin değerleri Tablo 1'de verilmiştir [23].
Tablo 1. Hesaplanan parametrelerin değerleri [23] (Values of the calculated parameters)

\begin{tabular}{lc}
\hline Toplam boru sayısı & $1260 \mathrm{adet}$ \\
$\begin{array}{l}\text { Borulardaki faz değişim malzemesi } \\
\text { miktarı }\end{array}$ & $59,37 \mathrm{~kg}$ \\
$\begin{array}{l}\text { Isı transfer yüzey alanı } \\
\text { Boruların dış yüzeyindeki ısı taşınım }\end{array}$ & $31,67 \mathrm{~m}^{2}$ \\
katsayısı & $86 \mathrm{~W} / \mathrm{m}^{2} \mathrm{~K}$ \\
Havanın kütlesel debisi & \\
Havanın ısıl kapasitesi & $0,277 \mathrm{~kg} / \mathrm{s}$ \\
\hline
\end{tabular}

Şekil 2 ile verildiği gibi hesaplamalara 1.boru sırasından başlanılmakta ve hesaplamalar sonucu elde edilen çıkış sıcaklığı 2.boru sırasının giriş sıcaklığı olarak alınmaktadır. Aynı hesaplama yöntemi sonuncu boru sırasına kadar uygulanmaktadır. Burada sıra sayıları $n$ ile gösterilmiştir. Son sıra sayısı ise $N_{p}$ ile verilmiştir. Boru içindeki sıvı kütlesinin tüm kütleye oranı ergime oranıdır ve $f_{m}$ ile gösterilmiştir. Bir boru sırası için toplam transfer yüzey alanı, $A_{n}=A / N_{p}$ şeklinde tanımlanabilir. $n$. boru sırasının üzerine akan havanın sıcaklığı $T_{n}$, havanın boru sirası üzerinden ayrılma sıcaklığı $T_{n+l}$ 'dir. $n$. boru sırası tarafindan çekilen isı $q_{n}$ ve bu boru sırasındaki ergime oranı $f_{m, n}$ ile verilmiştir. Hesaplamalar $\Delta t_{j}$ zaman aralığı için gerçekleştirilmiştir. Faz değişim malzemenin anlık ergime oranı $f_{m}(n, t)$ ve anlık 1Sı transferi $q(n, t)$, her sıra için gizli 1sı kapasitesine bağlıdır ve Eş. (6 ve 7) ile ifade edilmiştir [23].

$Q_{n}=\frac{Q_{0}}{N_{p}}=\frac{m_{F D M} L}{N_{p}}$

$\frac{\partial f_{m}}{\partial t}=\frac{q_{n}}{Q_{n}}$

Herhangi bir $t$ anında havadan $n$-boru sirasina birim zamanda gerçekleşen $1 s 1$ transferi Eş. 8 ile verilmiş̧ir.

$q_{n}=A_{n} h_{e f f}\left[T_{\text {ort }}-T_{m}\right]$

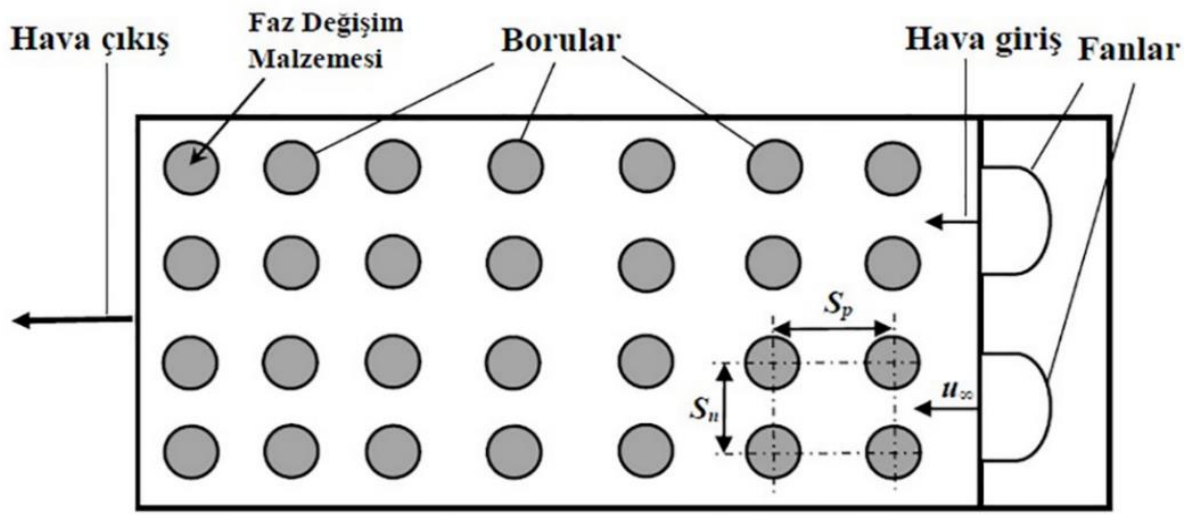

Şekil 1. Isı değiştiricisinin genel yapısı (General structure of the heat exchanger) 


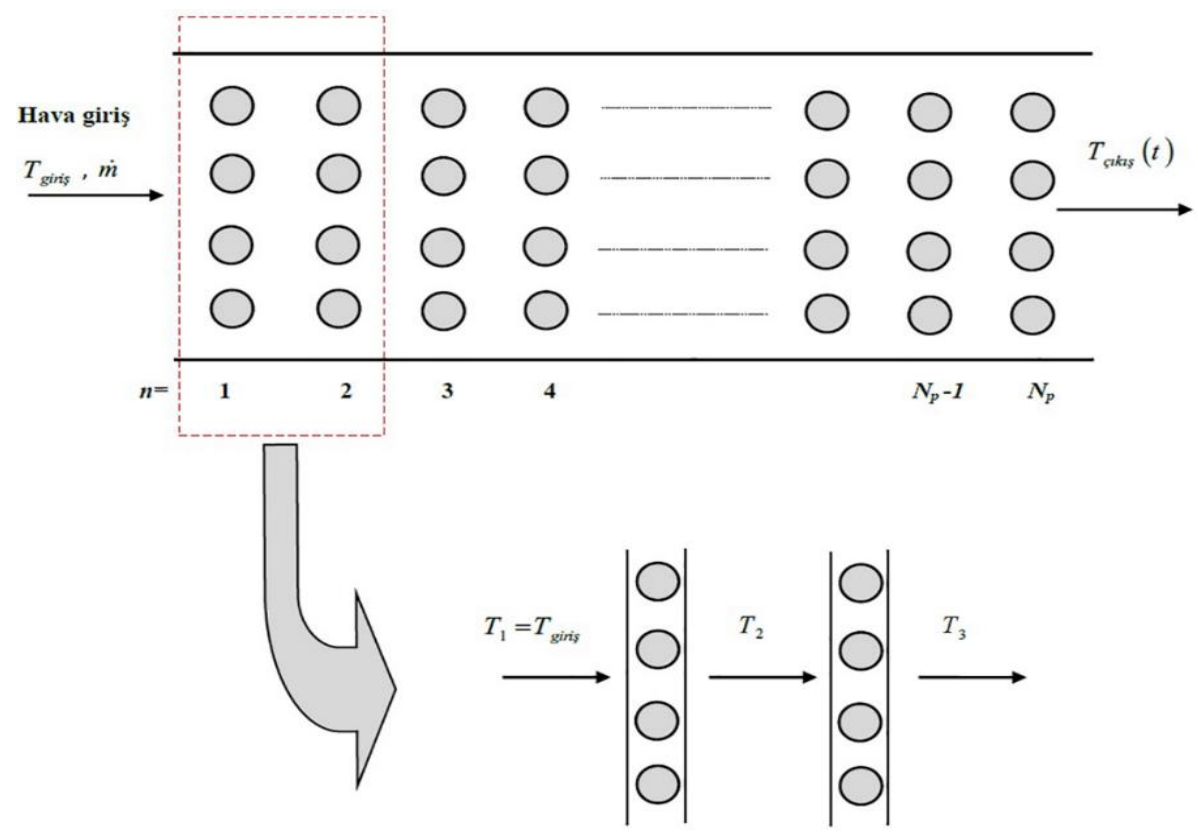

Şekil 2. Faz değişimli 1sı değiştiricisinin sayısal modeli (Numerical model of the phase change material heat exchanger)

Burada, $T_{\text {ort }}, n$-boru sırası için ortalama sıcaklık değeridir ve Eş. 9 ile ifade edilmiştir.

$T_{\text {ort }}=\frac{T_{n}+T_{n+1}}{2}$

Eş. 9'da yer alan $T_{n}$, n'inci boru sırasındaki hava giriş sıcaklığıdır ve $q_{n}(t=0)=0$ ile belirlenmektedir. Etkin 1 s1 transfer katsayısı $h_{\text {eff }}$ ise Eş. 10 ile hesaplanmıştır.

$$
h_{e f f}=\frac{1}{\left(\frac{1}{h_{t+\text { hava }}}+R_{l}\right)}=\frac{1}{\left(\frac{1}{h_{t+\text { hava }}}-\frac{D_{i c s}}{4 k_{F D M}} \log \left(1-f_{m}\right)\right)}
$$

Eş.10 ile verilen $h_{t+h a v a}$ ise hava ile borunun iç yüzeyi arasındaki etkin isı transfer katsayısıdır ve borunun iç çapına bağlı olarak Eş. 11 ile hesaplanmıştır [24].

$$
h_{t+h a v a}=\frac{1}{\frac{D_{i c \zeta}}{D_{\text {dls }} h_{\text {hava }}}+\frac{D_{i \underline{\zeta}}}{2 k_{t}} \log \left(\frac{D_{d l s}}{D_{i \zeta}}\right)}
$$

Boruların dış yüzeyindeki 1sı taşınım katsayısı, $h_{\text {hava }}$, hesabı için Eş. 12 ile verilen Grimson bağıntısı kullanılmıştır [26].

$$
\frac{h_{\text {hava }} D_{\text {dls }}}{k_{\text {hava }}}=c\left[\frac{v_{\max } \times D_{d l s}}{v_{\text {hava }}}\right]^{n} \operatorname{Pr}^{1 / 3}
$$

Eş. 12 ile verilen $(c)$ ve $(n)$ değerleri sabittir [26]. Düzgün sıralı 1S1 değiştiricisinde minimum geçiş alanındaki maksimum hava hızı Eş. 13 ile verilmiştir.

$$
v_{\max }=v_{0}\left(\frac{S_{n}}{S_{n}-D_{d l s}}\right)
$$

$t$ anındaki birim zamanda gerçekleşen 1 sı transferi miktarı Eş. 14 ile verilmiştir [24].

$$
q_{n}=\frac{A_{n}}{\frac{1}{h_{t+h a v a}}-\frac{D_{i c ̧}}{4 k_{F D M}} \log \left(1-f_{m}\right)}\left(T_{\text {ort }}-T_{m}\right)
$$

Eş. (7), sonlu farklar kullanılarak Eş. 15 ile ifade edilmiştir.

$$
f_{m \cdot n}(t+\Delta t)=f_{m \cdot n}(t)+\frac{q_{n} \Delta t}{Q_{F D M}}
$$

Başlangıçta $f_{m, n}(t=0)=0$ olarak alınmıştır. Zamana bağlı isı girdisi $q(n, t)$ ise, Eş. 16 ile gösterilmiştir [24].

$$
\left(\dot{m} c_{p} \frac{\partial T}{\partial n}\right)_{\text {hava }}=-q_{n}(n, t)
$$

Her sıra için hava çıkış sıcaklığı ise Eş. 17 ile ifade edilir.

$$
T_{n+1}=T_{n}-\frac{q_{n}}{\left(\dot{m} c_{p}\right)_{\text {hava }}}
$$

Sabit giriş sıcaklığı olan 1sı değiştiricisinin çözümü için bilgisayar programı yardımı ile iteratif bir süreç uygulanarak sonuçlar elde edilmiştir. Her zaman adımında ve her bir boru sırası için (14), (15) ve (17) eşitlikleri kullanılarak iteratif çözümleme yapılmıştır. Yakınsama kriteri Eş. 18'deki gibi ifade edilmiştir. 


$$
\frac{f_{m}-f_{m}^{\text {old }}}{f_{m}} \leq 10^{-8}
$$

Problemin çözümünde $\Delta t=0,1 \mathrm{~s}$ zaman adımı olarak belirlenmiştir. Bilgisayar programına ait akış şeması Şekil 3 'te gösterilmiştir. Anlık ısı transfer miktarı boyutsuz olarak Eş. 19 ile verilmiştir.

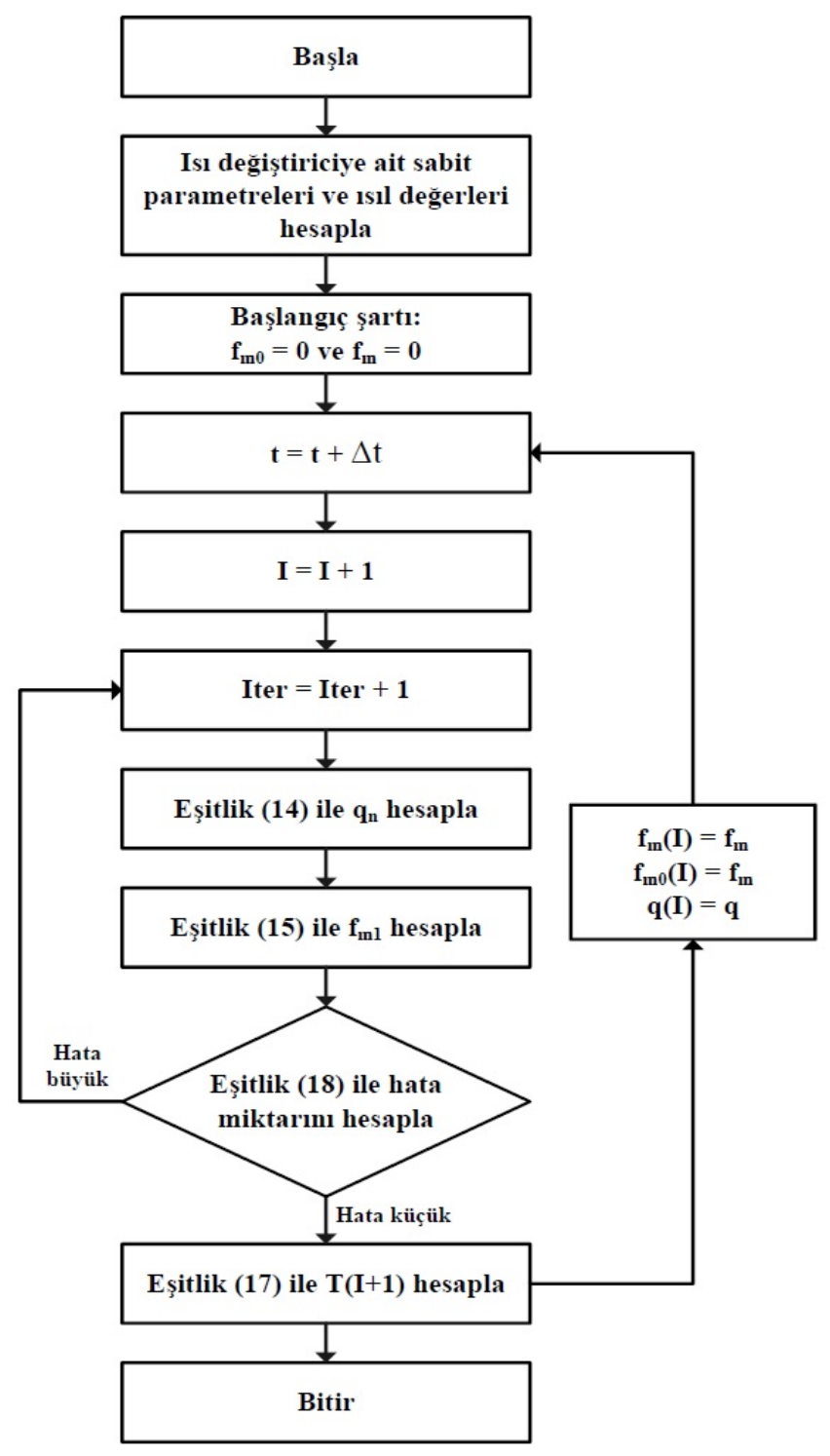

Şekil 3. Bilgisayar programı akış şeması

(Flow chart of the computer program)

$$
q_{0}=\frac{q_{n}}{q_{\max }}=\frac{q_{n}(n, t)}{\left(\dot{m} c_{p}\right)_{\text {hava }}\left(T_{\text {giris }}-T_{m}\right)}
$$

Parametrik çalışma hesaplamaları için boru aralığı oranı Eş. 20 ile tanımlanmıştır.

$$
R=\frac{S_{n} / D}{S_{p} / D}
$$

Fan işi hesabı ise Eş. 21 ile tanımlandığı gibidir.

$$
W_{\text {fan }}=\left(\frac{\dot{m}}{\rho}\right)_{\text {hava }} \frac{\Delta P}{\eta}
$$

Burada fan verimi $(\eta)$ 0,5 olarak alınmıștır. Toplam basınç düşümü $(\Delta P)$ boru demeti üzerinde meydana gelen akış sonucu oluşan basınç düşümü bağıntısından hesaplanır [26].

\section{SONUCLAR VE TARTISMALAR (RESULTS AND DISCUSSIONS)}

Sabit hava giriş sıcaklığı durumu için faz değişim malzemeli bir 1sı değiştirici sayısal olarak incelenmiş ve sonuçlar Dubovsky vd. [24] tarafindan yapılan analitik yöntemi ile karşılaştırmalı olarak sunulmuştur. Farklı boru sayılarının boyutsuz anlık 1S1 transferi miktarına etkisi Şekil 4 ile karşılaştırmalı olarak gösterilmektedir. Boru sayısı arttıkça sistem daha uzun süre kapsamında istenilen soğutma yükünü sağlamaktadır. Şekil 4'de görüldüğü gibi $\left(N_{p}=10\right)$ için yaklaşık olarak 1000s'de ergimekte, $\left(N_{p}=90\right)$ için yaklaşık olarak 4250s'de ergimektedir. Isı değiştiricinin çektiği enerjinin boyutsuz olarak zamana göre değişimi farklı boru sayıları için Şekil 5'te karşılaştırmalı olarak sunulmaktadır. Boru sayısı arttıkça 1sı değiştiricisinin çektiği enerji artmaktadır ve ayrıca boru sayısının artışıyla analitik ile sayısal çözümün arasındaki fark daha azaldığ görülmüştür. Boyutsuz anlık 1sı transfer miktarının zamana göre değişimleri farklı hava giriş sıcaklıkları için karşılaştırmalı olarak Şekil 6'da verilmiştir. Hava giriş sıcaklığı $\operatorname{arttıkça~}\left(\Delta T=T_{\text {giriş }}-T_{m}\right)$ değeri yeterince fazla olduğu için ergime hızı da artmaktadır. Ayrıca $(\Delta T=71$ $\left.23^{\circ} \mathrm{C}\right)$ iken ergime süresi yaklaşık olarak 1000s; $(\Delta T=35$ $23^{\circ} \mathrm{C}$ ) iken ergime süresi yaklaşık olarak 4300s olarak tespit edilmiştir. Şekil 7'de 1sı değiştiricinin çektiği boyutsuz enerji farklı hava giriş sıcaklıkları için karşılaştırmalı olarak gösterilmiştir. Benzer şekilde $\Delta T$ farkı arttıkça 1S1 değiştiricinin çektiği toplam enerjinin hızlı bir şekilde maksimum değere ulaştığı görülmektedir. Faz değişim malzemeli 1sı değiștirici soğutma amacı ile kullanılmaktadır ve bu sebepten dolayı hava debisi (fan hızı) etken çalışma parametrelerinden biridir. Boyutsuz anlık 1s1 transfer miktarının zamana göre değişimi farklı hava debisi değerleri için Şekil 8'de karşılaştırmalı olarak gösterilmiştir. Şekil 8'de hava debisi değişimi için Grimson bağıntısı [26] kullanılmıştır ve bu bağıntının kullanılması sonucunda boru dışındaki 1Sı taşınım katsayısının fan hızının fonksiyonu olarak değiştiği görülmüştür. Bu etkinin sonucunda anlık 1S1 transfer miktarı da değişmektedir. Hava debisi arttıkça anlık 1S1 transfer miktarı artmış ve buna bağlı olarak sistemin ergime hızı da artmıştır. $v=4 v_{0}$ iken ergime süresi yaklaşık olarak 1300s, $v=0,5 v_{0}$ iken ergime süresi yaklaşık olarak 8100 s'dir. Şekil 9'da 1sı değiştiricisinin çektiği boyutsuz enerjinin zamana göre değişimi farklı hava debisi değerleri için karşılaştırmalı olarak verilmiştir. Benzer şekilde hava debisi arttığı zaman 1sı değiştiricinin çektiği toplam enerjinin ivedilikle maksimum değerine ulaştığ görülmüştür. 


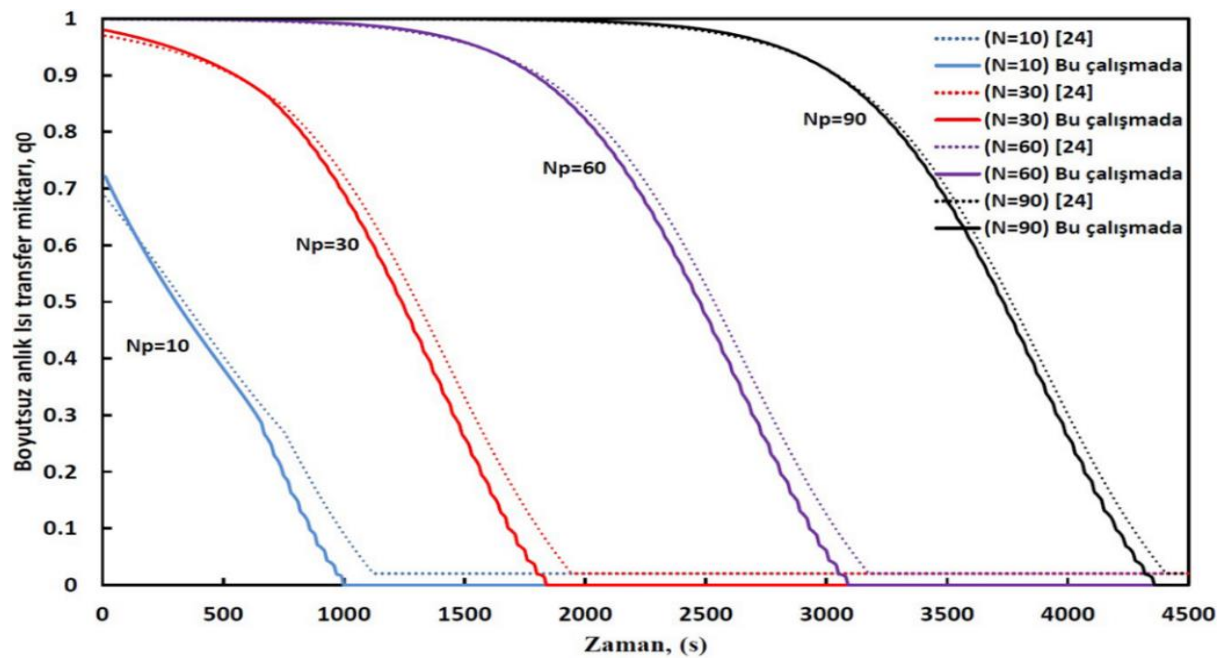

Şekil 4. Farklı boru sayıları için boyutsuz anlık 1Sı transfer miktarının zamana göre değişimi [24] (Variation of the dimensionless instantaneous heat transfer rates with time for different number of tubes)

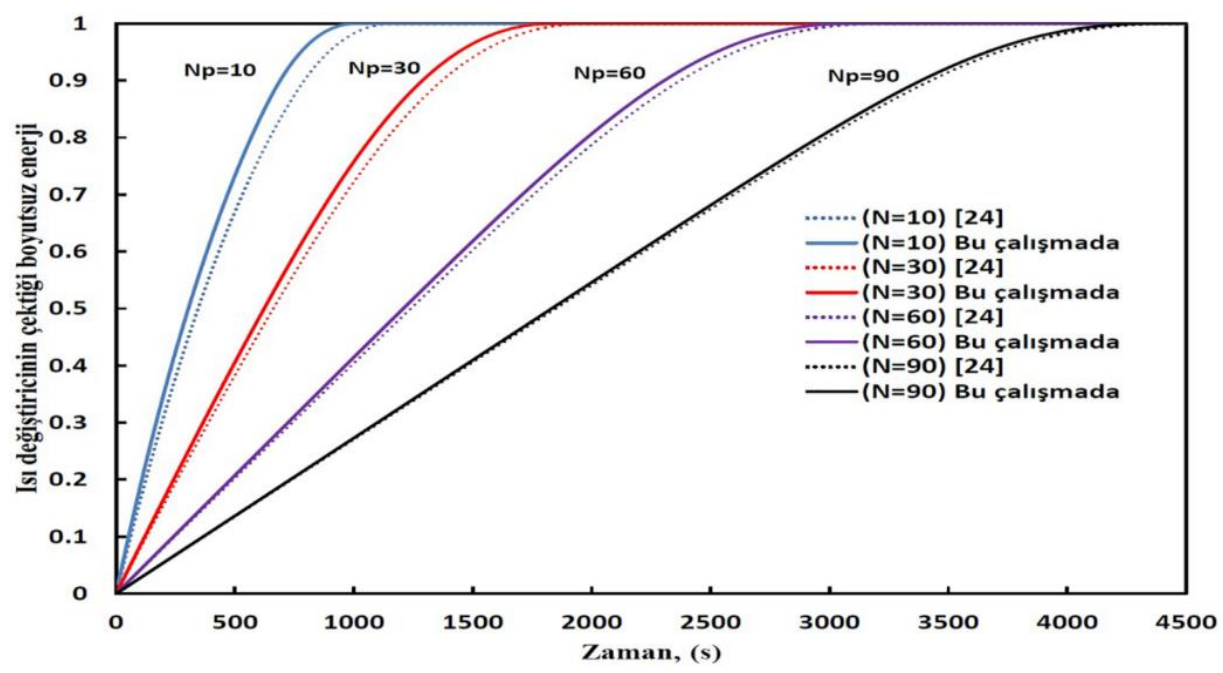

Şekil 5. Faz değişimli 1sı değiştiricisinin sayısal modeli [24] (Numerical model of the phase change material heat exchanger)

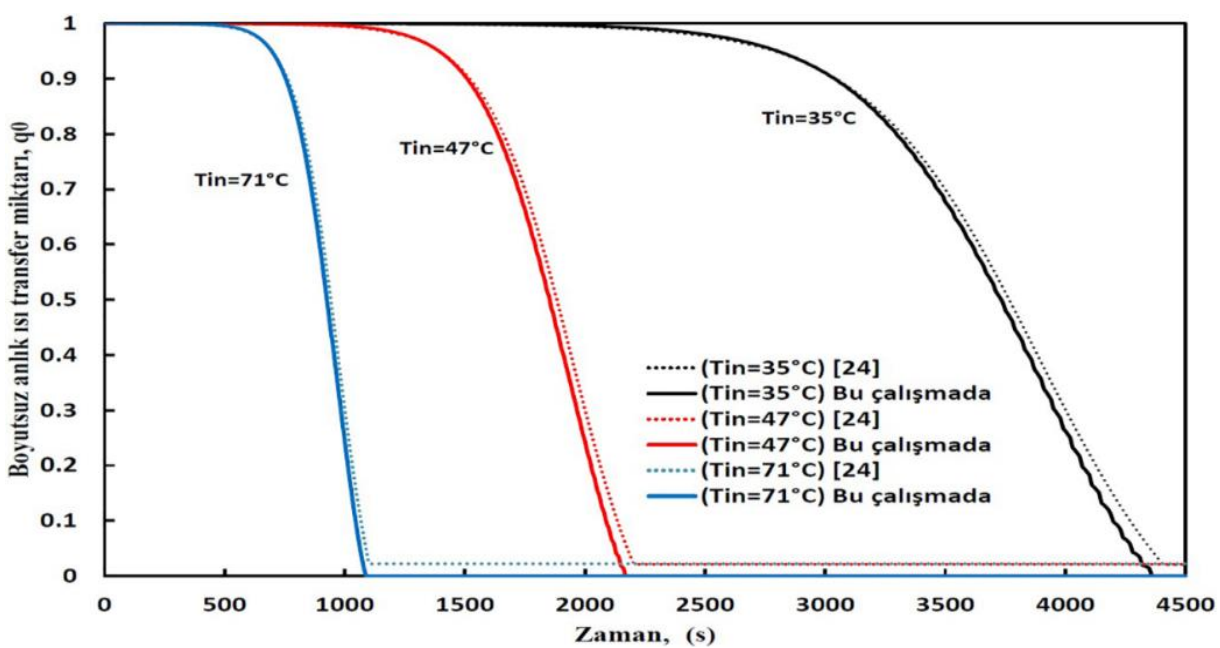

Şekil 6. Farklı hava giriş sıcaklıkları için boyutsuz anlık ısı transfer miktarlarının değişimi [24] (Variation of the dimensionless heat transfer rates for different inlet temperatures) 
Tablo 2. Boru aralıklarının değişimine göre elde edilen değerler (Results obtained according to tube pitch variations)

\begin{tabular}{|c|c|c|c|c|c|c|c|c|c|}
\hline$S_{n} / D$ & $R$ & $\begin{array}{c}N_{n} \\
\text { (adet) }\end{array}$ & $\begin{array}{l}N_{\text {toplam }} \\
\text { (adet) }\end{array}$ & $\begin{array}{l}M_{F D M} \\
(\mathrm{~kg} / \mathrm{s})\end{array}$ & $\begin{array}{c}h_{\text {hava }} \\
\left(W / m^{2} K\right)\end{array}$ & $\begin{array}{l}\text { Toplam ergime } \\
\text { zaman1 (s) }\end{array}$ & $\begin{array}{l}\Delta \mathrm{P} \\
(\mathrm{Pa})\end{array}$ & $\begin{array}{c}W \\
(W)\end{array}$ & $Q / t_{e r} W$ \\
\hline 1,25 & 1 & 16 & 1728 & 76,43 & 129,38 & 5500 & 2400,3 & 1129,1 & 2,7012 \\
\hline 1,5 & 1,2 & 14 & 1512 & 71,251 & 85,726 & 5085,6 & 406,505 & 191,219 & 15,09 \\
\hline 2 & 1,6 & 10 & 1080 & 50,89 & 50,026 & 4059,8 & 93,373 & 43,9225 & 58,79 \\
\hline 3 & 2,4 & 7 & 756 & 35,6257 & 36,554 & 3320,6 & 31,862 & 14,988 & 147,45 \\
\hline \multicolumn{10}{|c|}{$S_{p} / D=1,5-N_{p}=90$} \\
\hline$S_{n} / D$ & $R$ & $\begin{array}{c}N_{n} \\
\text { (adet) }\end{array}$ & $\begin{array}{l}N_{\text {toplam }} \\
\text { (adet) }\end{array}$ & $\begin{array}{l}M_{F D M} \\
(\mathrm{~kg} / \mathrm{s}) \\
\end{array}$ & $\begin{array}{c}h_{\text {hava }} \\
\left(W / m^{2} K\right)\end{array}$ & $\begin{array}{c}\text { Toplam ergime } \\
\text { zaman1 (s) }\end{array}$ & $\begin{array}{l}\Delta \mathrm{P} \\
(\mathrm{Pa})\end{array}$ & $\begin{array}{c}W \\
(W)\end{array}$ & $Q / t_{e r} W$ \\
\hline 1,25 & 0,833 & 16 & 1440 & 67,858 & 129,721 & 4767,4 & 1951,2 & 917,865 & 3,1946 \\
\hline 1,5 & 1 & 14 & 1260 & 59,3 & 85,899 & 4353 & 362,12 & 170,339 & 16,4959 \\
\hline 2 & 1,3 & 10 & 900 & 42,411 & 49,726 & 3540,2 & 88,617 & 41,68 & 59,2 \\
\hline 3 & 2 & 7 & 630 & 29,68 & 36,96 & 2946,4 & 30,73 & 14,456 & 143,58 \\
\hline \multicolumn{10}{|c|}{$S_{p} / D=2,0-N_{p}=67$} \\
\hline$S_{n} / D$ & $R$ & $\begin{array}{c}N_{n} \\
\text { (adet) }\end{array}$ & $\begin{array}{l}N_{\text {toplam }} \\
\text { (adet) }\end{array}$ & $\begin{array}{l}M_{F D M} \\
(\mathrm{~kg} / \mathrm{s})\end{array}$ & $\begin{array}{c}h_{\text {hava }} \\
\left(W / m^{2} K\right)\end{array}$ & $\begin{array}{l}\text { Toplam ergime } \\
\text { zaman (s) }\end{array}$ & $\begin{array}{l}\Delta \mathrm{P} \\
(\mathrm{Pa})\end{array}$ & $\begin{array}{c}W \\
(W)\end{array}$ & $Q / t_{e r} W$ \\
\hline 1,25 & 0,625 & 16 & 1072 & 50,516 & 129,284 & 3699,2 & 1489,1 & 700,495 & 4,016 \\
\hline 1,5 & 0,75 & 14 & 938 & 44,2 & 88,99 & 3406,6 & 309,07 & 145,386 & 18,38 \\
\hline 2 & 1 & 10 & 670 & 31,57 & 66,77 & 2734,4 & 82,0614 & 38,602 & 61,62 \\
\hline 3 & 1,5 & 7 & 469 & 22,1 & 54,1 & 2248,8 & 29,36 & 13,81 & 146,58 \\
\hline \multicolumn{10}{|c|}{$S_{p} / D=3,0-N_{p}=45$} \\
\hline$S_{n} / D$ & $R$ & $\begin{array}{c}N_{n} \\
\text { (adet) }\end{array}$ & $\begin{array}{l}N_{\text {toplam }} \\
\text { (adet) }\end{array}$ & $\begin{array}{l}M_{F D M} \\
(\mathrm{~kg} / \mathrm{s})\end{array}$ & $\begin{array}{c}h_{\text {hava }} \\
\left(\mathrm{W} / \mathrm{m}^{2} K\right) \\
\end{array}$ & $\begin{array}{l}\text { Toplam ergime } \\
\text { zaman1 }(s)\end{array}$ & $\begin{array}{l}\Delta \mathrm{P} \\
(\mathrm{Pa})\end{array}$ & $\begin{array}{c}W \\
(W)\end{array}$ & $Q / t_{e r} W$ \\
\hline 1,25 & 0,41 & 16 & 720 & 33,929 & 116,415 & 2699,6 & 1145,5 & 538,826 & 4,805 \\
\hline 1,5 & 0,5 & 14 & 630 & 29,688 & 92,09 & 2501,8 & 265,305 & 124,799 & 19,587 \\
\hline 2 & 0,66 & 10 & 450 & 21,205 & 74,476 & 2053,8 & 76,73 & 36,0914 & 58,92 \\
\hline 3 & 1 & 7 & 315 & 14,84 & 58,45 & 1764,6 & 28,75 & 13,52 & 128,12 \\
\hline
\end{tabular}

Bunun yanında faz değişimli 1 sı değiştiricisine etkiyen çalışma parametreleri de parametrik olarak incelenmiștir. Yapılan parametrik çalışmada soğutucu hacmi sabit tutulmuştur. Boru aralığı değişimi, hava debisi (fan hızı) değişimi ve faz değişim malzemesi değişken parametreler olarak ele alınmıştır. Boru aralığının değişimine göre toplam boru sayısı ve faz değişim malzemenin kütlesi değiştirilmiştir. Farklı boru aralıkları Tablo 2'de verilmiştir. Tablo 2'de verildiği gibi fan gücü daha yüksek oranda azalırken toplam ergime zamanı değişimi $S_{p} / D=1,25$ durumu için $\% 39, S_{p} / D=1,5$ durumu için $\% 38, S_{p} / D=2,0$ durumu için $\% 39, S_{p} / D=3,0$ için $\% 34$ olarak değişmektedir. Boru aralığı oranı $(R)$ azaldığı zaman toplam ergime zamanı $\left(t_{e r}\right)$ artmasına rağmen fan işi $(W)$ artmaktadır. Bu iki etkinin beraber incelemesi için $\left(Q / t_{e r} W\right)$ gibi bir performans indeksi tanımlanabilir. $S_{n} / D$ azaldıkça fan işindeki artış miktarı performans oranını da oldukça azaltmaktadır. Ayrıca Tablo 2'ye göre boru aralığın değişimi incelenmiş ve ilgili grafikler sırasıyla Şekil (10 ve 11)'de gösterilmiștir. Her $S_{p} / D$ değeri için $S_{n} / D$ arttıkça toplam boru sayısı azalmakta ve buna bağlı olarak faz değişim malzemenin miktarı da azalmaktadır. Bunun sonucu olarak toplam ergime zamanı azalmaktadır. Ayrıca $S_{p} / D$ 'nin artışı her $S_{n} / D$ için ergime hızını arttırmakta ve toplam ergime zamanını ise azaltmaktadır. Hava debisindeki değişiklikleri incelemek için Tablo 2'de verilen $S_{p} / D=2$ ve $N_{p}=67$ değerleri göz önünde tutulmuştur. Toplam ergime zamanı boru aralığın oranına göre $(R)$ farklı hava debileri için $\left(v=0,5 v_{0}, v_{0}, 1,5 v_{0}\right.$, $\left.2 v_{0}\right)$ Şekil 12 ile gösterilmiştir. Hava debisi arttıkça ergime hızı artmakta ve toplam ergime zamanı azalmaktadır. Ayrıca toplam ergime zamanının soğutucuya giren hava sıcaklığına göre değişimi farklı hava debileri için Şekil 13 'te gösterilmiştir.

Tablo 2'den alınan $S_{p} / D=1,5$ ve $\mathrm{S}_{\mathrm{n}} / D=1,5$ parametreleri kullanılmıştır ve hava debisi arttıkça toplam ergime zamanının azaldığı görülmüştür. Ayrıca hava giriş sıcaklığı $30^{\circ} \mathrm{C}$ iken hava debisi ve $R e$ sayısının etkisinin fazla olduğu görülmüştür. Hava giriş sıcaklığ $150^{\circ} \mathrm{C}$ iken hava debisi ve $R e$ sayısının etkisi azdır. Fan hızı artıkça $R e$ sayısı artar ve boruların dış yüzeyindeki ısı taşınım katsayısı artmasıyla toplam direnç azalır. Şekil 13 ile verilen grafiğin eğiminin Esen ve Ayhan [15] tarafindan verilen sonuçlar ile benzeștiği görülmüştür. Faz değişim malzemesinin sistem performansina olan etkisi Tablo 2'den alınan $\mathrm{S}_{\mathrm{p}} / D=1,5$ durumu için incelenmiștir. Faz değișim malzemesinin etkisini incelemek için $S t e=c_{p}\left(T_{i n}-T_{m}\right) / L$ olarak tanımlanan Stefan sayısı kullanılmıştır. Toplam ergime zamanının boru aralığı oranına göre değişimi farklı Stefan sayıları için Şekil 14 'te verilmektedir. Stefan sayısının artması ile toplam gizli 1S1 miktar1 ve toplam ergime zamanı azalmaktadır. Boru aralığı oranı $(R)$ artıkça boru sayısı ve faz değişim malzemenin kütlesi azalmaktadır. Dolaysıyla toplam ergime zamanı da azalmaktadır. 


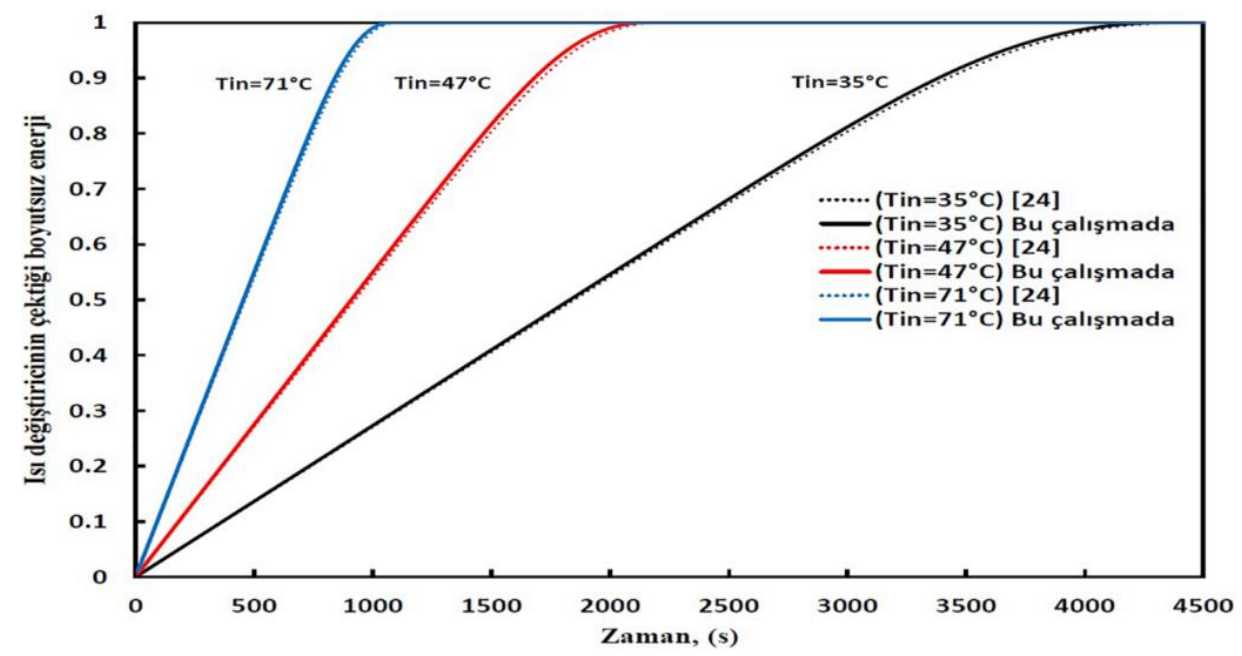

Şekil 7. Farklı hava giriş sıcaklıkları için çekilen boyutsuz enerji miktarının zamana bağlı olarak değişimi (Variation of dimensionless absorbed energy with time for different inlet temperatures)

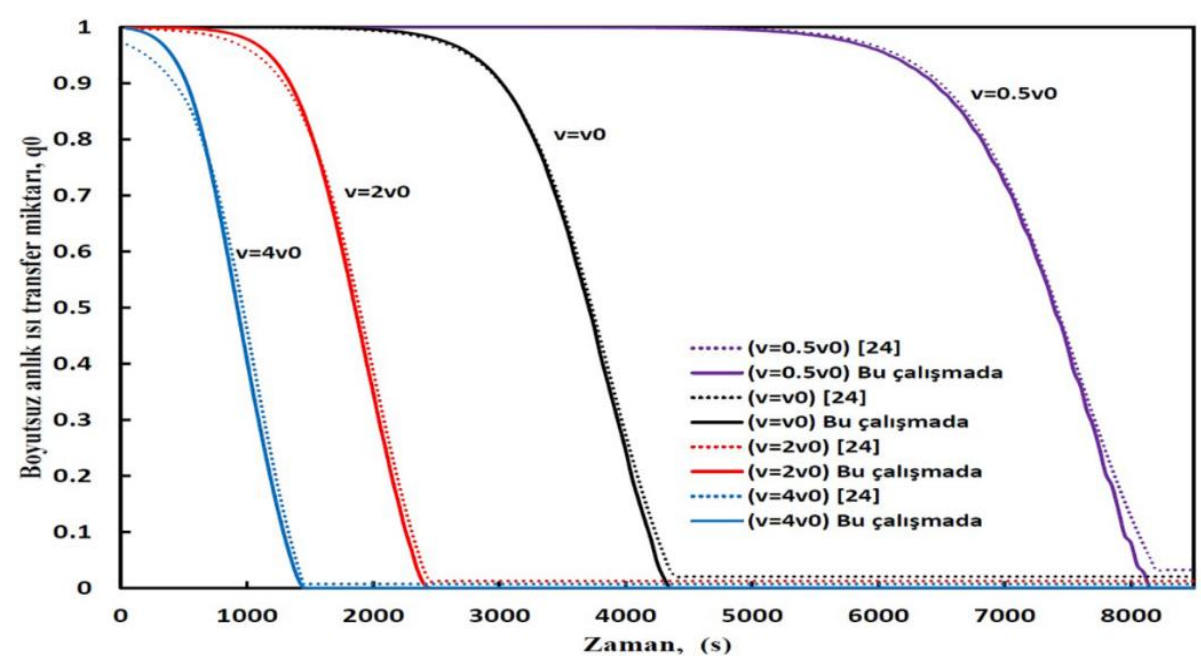

Şekil 8. Farklı hava debileri için boyutsuz anlık ısı transfer miktarı (Variation of instantaneous dimensionless heat transfer rate for different air flow rates)

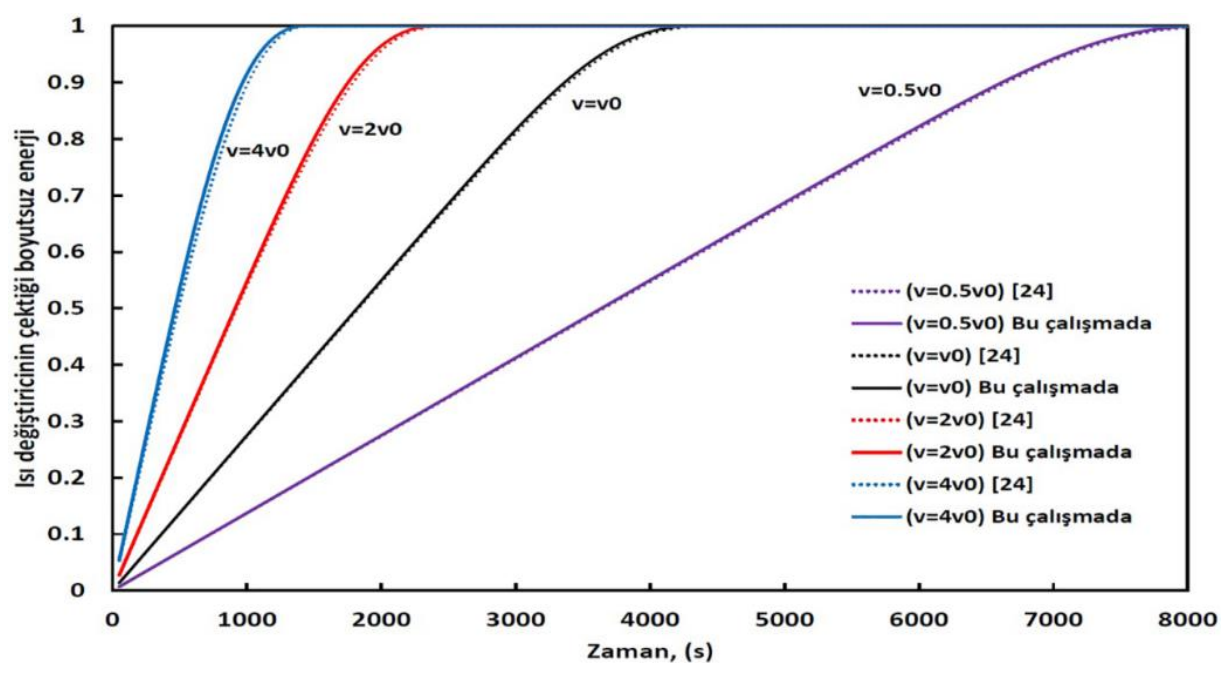

Şekil 9. Farklı hava debileri için çekilen boyutsuz enerji miktarları (Variation of dimensionless absorbed energy for different air flow rates) 


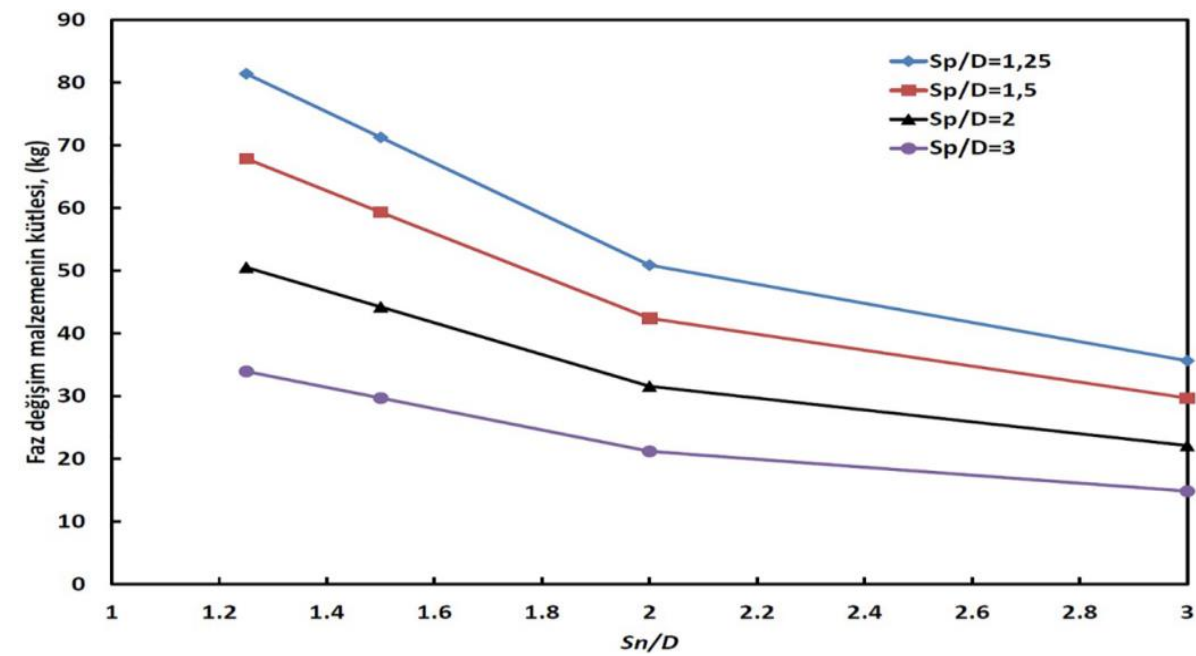

Şekil 10. Faz değişim malzemenin kütlesinin boru aralığına göre değişimi (Variation of mass of the phase change material with tube pitch)

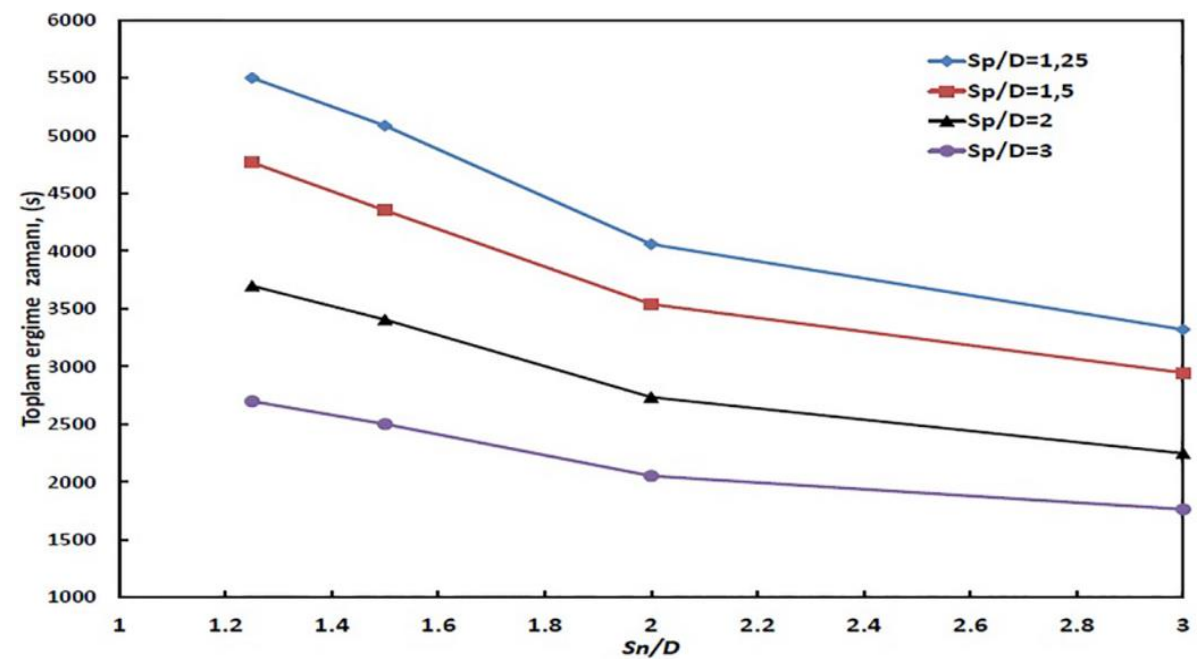

Şekil 11. Toplam ergime zamanının boru aralığına göre değişimi (Variation of total melting time with tube pitch)

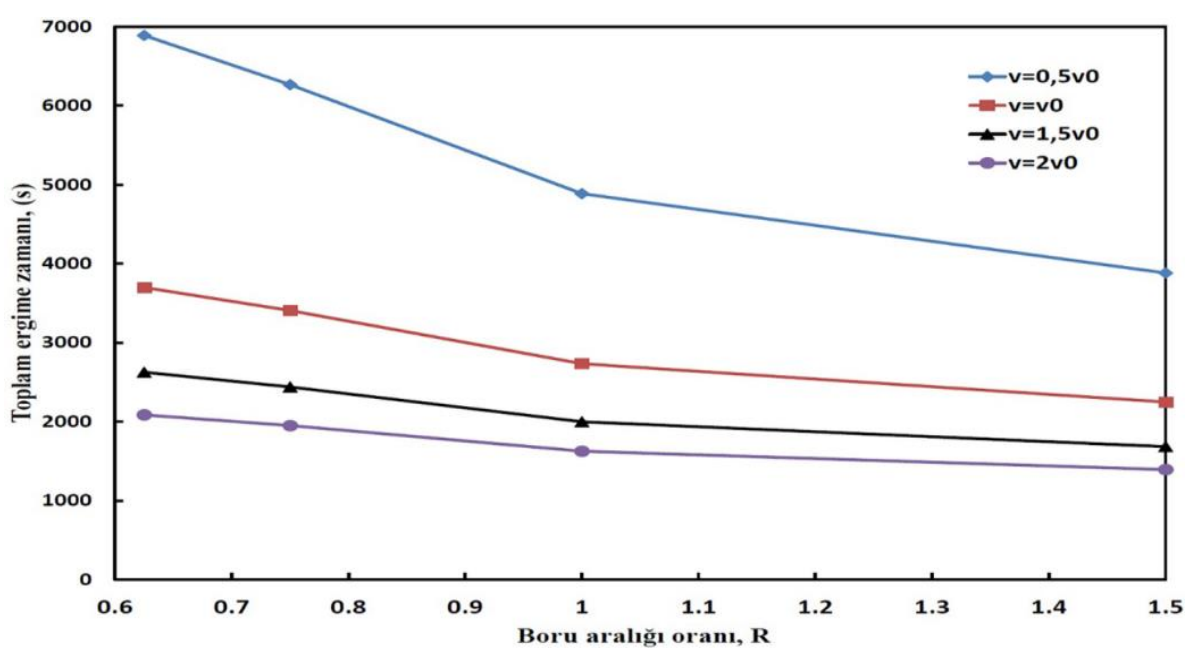

Şekil 12. Toplam ergime zamanının farklı hava debilerine göre değişimi (Variation of total melting time for different mass flow rates ) 


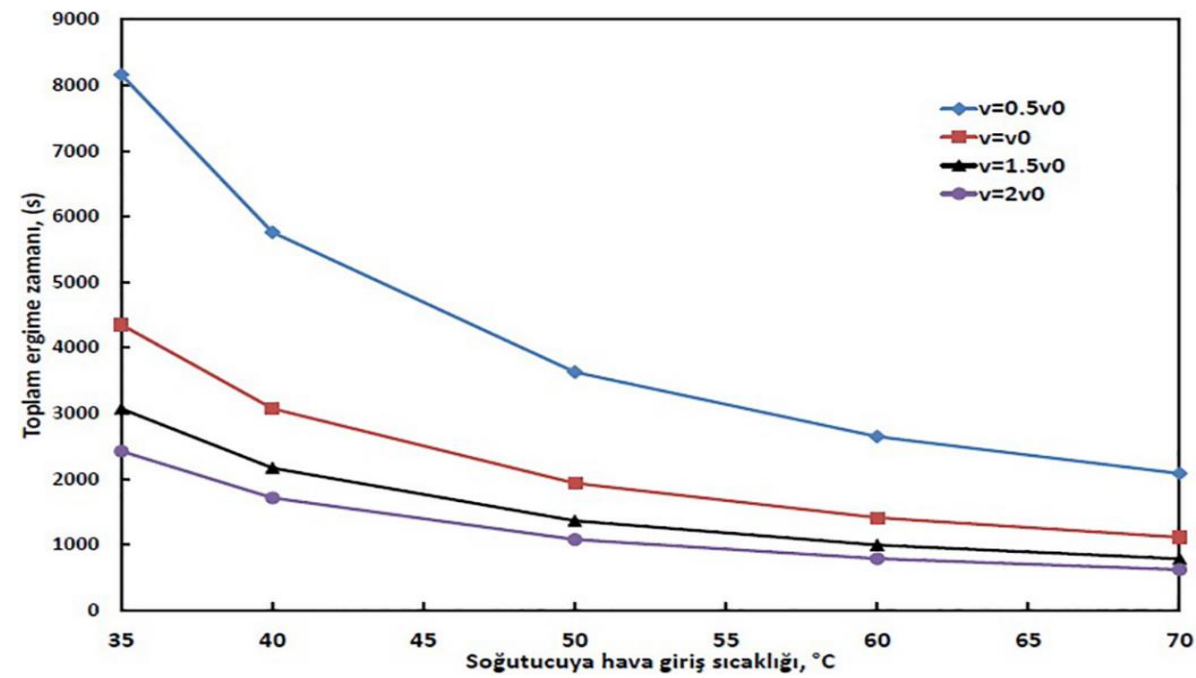

Şekil 13. Farklı hava debiler için toplam ergime zamanının soğutucuya giren farklı hava sıcaklıklarına göre değişimi (Variation of total melting time with inlet temperatures for different mass flow rate)

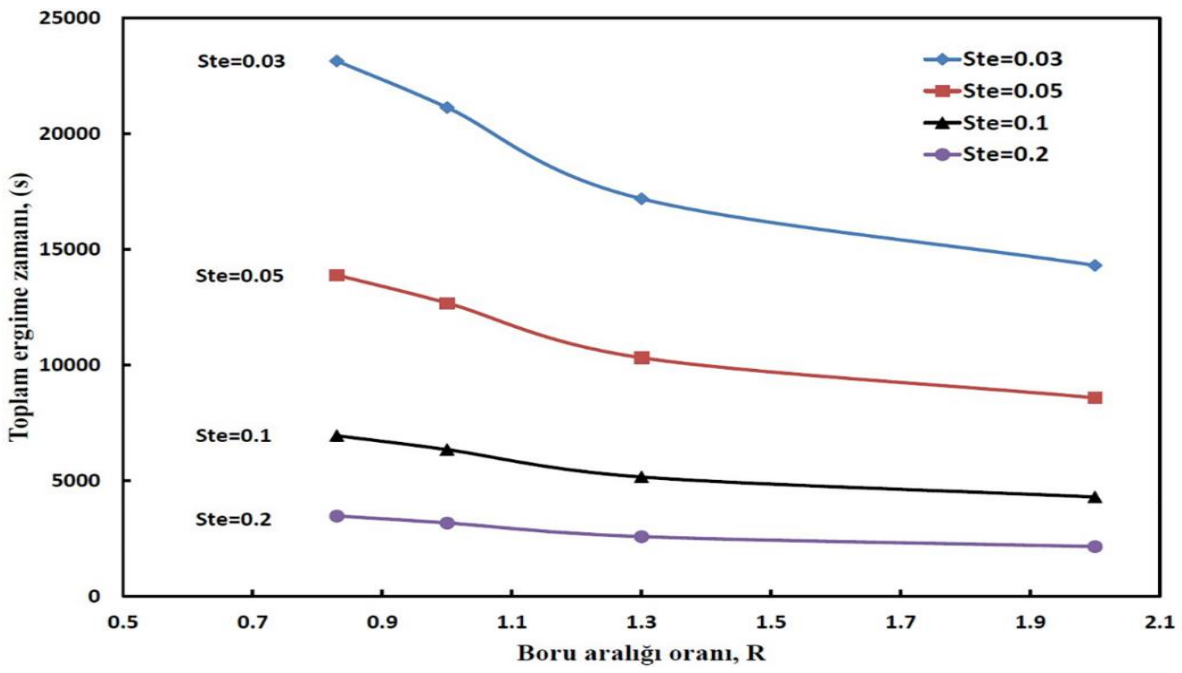

Şekil 14. Toplam ergime zamanının boru aralığg oranına göre değişimi (Variation of total melting time with tube pitch )

\section{SONUÇLAR (CONCLUSIONS)}

Bu çalıșma kapsamında borularının içinde faz değișim malzemesi olan bir 1sı değiştiricisinin soğutma amac1 ile kullanılacağı tasarıma ait 1 sıl hesaplar verilmiştir. Isı değiştiricisi üzerine fanlar aracıllı̆ı ile üflenen sıcak hava, borular içinde bulunan faz değişim malzemesini eriterek soğuyan havanın 1S1 değiştiricisinden çıkmasını sağlamaktadır. Isıl hesapların yanında faz değişimli isı değiştiricisi için sayısal bir çözüm de verilmiştir. Giriş verileri olarak sabit hava giriș sıcaklığ 1 ve sabit hava debisi alınmıştır. Soğutma sistemi literatürde yer alan analitik çözümler ile de karşılaştırılmış ve sistem için parametrik bir inceleme yapılmıștır. Yapılan çalışmada 1sı değiștiricisinin hacmi sabit tutulmuş ve aşağıda verilen sonuçlar elde edilmiştir: Boru aralığı arttığında boru sayısının azaldığı, faz değişim malzemesinin kütlesinin azaldığ 1 ve bundan dolayı toplam ergime zamanının azaldığı görülmüştür. Fan hızının artması ile toplam ergime zamanının azaldığ edilmiştir. Soğutucuya giren hava sıcaklığının artması ile toplam ergime zamanının azaldığı görülmüştür. Boru sayısı akışa dik yönde iki kat arttığında toplama ergime zamanı tüm dört aralık durumu için ortalama olarak \%38 oranında azalmıştır.

\section{SEMBOLLER (SYMBOLS)}

A Isı transferi yüzey alanı $\left(\mathrm{m}^{2}\right)$

$c_{p} \quad$ Özgül 1sı (J/kgK)

$D_{b} \quad$ Boru diș çapı $(\mathrm{m})$

$D_{i c} \quad$ Boru iç çapı (m)

$f_{m} \quad$ Ergime oran 1

$h_{\text {eff }} \quad$ Etkin $1 \mathrm{s1}$ transfer katsay $1 \mathrm{~s} 1\left(\mathrm{~W} / \mathrm{m}^{2} \mathrm{~K}\right)$

$h_{\text {hava }}$ Boru dış yüzeyindeki ısı taşınım katsayısı $\left(\mathrm{W} / \mathrm{m}^{2} \mathrm{~K}\right)$

$\mathrm{k} \quad \mathrm{Is} 1$ iletim katsayısı (W/mK)

$L \quad$ Gizli 1 1S1 $(\mathrm{J} / \mathrm{kg})$

$\dot{m}_{\text {hava }}$ Havanın kütlesel debisi ( $\left.\mathrm{kg} / \mathrm{s}\right)$ 


$\begin{array}{ll}m_{F D M} & \text { Faz değişim malzemesi kütlesi }(\mathrm{kg}) \\ N_{n} & \text { Akışa dik boru sayısı (adet) } \\ N_{p} \text { (adet) } & \text { Akışa paralel yöndeki boru sayısı } \\ P r & \text { Prandtl sayısı } \\ q_{0} & \text { Boyutsuz anlık ısı transferi miktarı } \\ Q_{0} & \text { Gizli ısı kapasitesi }(\mathrm{J}) \\ R_{t} & \text { Isıl direnç }\left(\mathrm{m}^{2} \mathrm{~K} / \mathrm{W}\right) \\ R_{l} & \text { Sivı tabakasının } 1 \mathrm{~S} 1 \mathrm{l} \text { direnci }\left(\mathrm{m}^{2} \mathrm{~K} / \mathrm{W}\right) \\ T_{i n} & \text { Giriş sıcaklı̆̆ }\left({ }^{\circ} \mathrm{C}\right) \\ T_{m} & \text { Ergime sıcaklığ }\left({ }^{\circ} \mathrm{C}\right) \\ T_{o r t} & \text { Ortalama sıcaklık }\left({ }^{\circ} \mathrm{C}\right) \\ v_{0} & \text { Havanın serbest akış hızı }(\mathrm{m} / \mathrm{s}) \\ v & \text { Kinematik viskozite }\left(\mathrm{m}^{2} / \mathrm{s}\right)\end{array}$

\section{KAYNAKLAR (REFEERENCES)}

1. Zalba B., Marin J.M., Cabeza L.F., Mehling H., Review on thermal energy storage with phase change: materials, heat transfer analysis and applications, Appl. Therm. Eng., 23 (2), 251-283, 2003.

2. Saito A., Recent advances in research on cold thermal energy storage, Int. J. Refrig. 25 (2), 177-189, 2002.

3. Garg HP., Solar Thermal Energy Storage, Springer 1985.

4. Zhao D., Tan G., Numerical analysis of a shell-andtube latent heat storage unit with fins for airconditioning application, Appl. Energy, 138, 381-392, 2015.

5. Navarro L., de Gracia A., Colclough S., Browne M., McCormack S.J., Griffiths P., Cabeza L.F., Thermal energy storage in building integrated thermal systems: A review. Part 1. active storage systems, Renewable Energy, 88, 526-547, 2016.

6. Navarro L., de Gracia A., Colclough S., Browne M., McCormack S.J., Griffiths P., Cabeza L.F., Thermal energy storage in building integrated thermal systems: A review. Part 2. Integration as passive system, Renewable Energy, 85, 1334-1356, 2016.

7. Ercoşkun G.T., Keskin A., Gürü M., Altıparmak D., Investigation of designing, manufacturing and performance of double- grooved parabolic trough-type solar collector Journal of the Faculty of Engineering and Architecture of Gazi University, 28 (4), 855-863, 2013.

8. Yildiz Y., Analysis of performance of night ventilation for residential buildings in hot-humid climates Journal of the Faculty of Engineering and Architecture of Gazi University, 29 (2), 385-393, 2014.

9. Çakır M.T., Improving the efficiency performance of heat pipes using alumina containing Nano-fluids, Journal of the Faculty of Engineering and Architecture of Gazi University, 30 (4), 547-556, 2015.

10. Dincer I., Rosen M.A., Thermal Energy Storage: Systems and Applications, Wiley, U.K. 2002.

11. Li G., Zheng $X$., Thermal energy storage system integration forms for a sustainable future, Renewable Sustainable Energy Rev., 62, 736-757, 2016.
12. Dietz D., Thermal Performance of a Heat Storage Module Using Calcium Chloride Hexahydrate, J. Sol. Energy Eng., 106 (1), 106-111, 1983.

13. Farid M.M., Kanzawa A., Thermal performance of a heat storage module using PCMs with different melting temperatures: mathematical modeling, J. Sol. Energy Eng., 111, 152-157, 1989.

14. Lacroix M., Numerical solution of a shell and tube latent heat thermal energy storage unit, Sol. Energy, 50 (4), 357-367, 1993

15. Esen M., Ayhan T., Development of a model compatible with solar assisted cylindrical energy storage tank and variation of stored energy with time for different phase change materials, Energy Convers. Manage., 37 (12), 1775-85, 1996.

16. Turnpenny J.R., Etheridge D.W., Reay D.A., Novel ventilation cooling system for reducing air conditioning in buildings I. testing and theoretical modeling, Appl. Therm. Eng., 20 (11), 1019-1038, 2000.

17. Turnpenny J.R., Etheridge D.W., Reay D.A., Novel ventilation cooling system for reducing air conditioning in buildings II. testing of a prototype, Appl. Therm. Eng., 21 (12), 1203-1217, 2000.

18. Vakilaltojjar S.M., Saman W., Analysis and modeling of a phase change storage system for air conditioning applications, Appl. Therm. Eng., 21 (3), 24-63, 2001.

19. Mozhevelov S., Cooling of structures by a phase change material (PCM) in Natural and Forced Convection M.Sc. thesis, Mechanical Engineering Department, Ben-Gurion University of the Negev, Beer-Sheva, Israel 2004.

20. Mozhevelov S., Ziskind G., Letan R., Numerical study of temperature moderation in a real size room by PCMbased units, Heat-SET, Heat Transfer in Components and Systems for Sustainable Energy Technologies, Grenoble, France, April 5-7, 2005.

21. Arye G., Guedj R., A PCM-based Conditioner, final report 13-04, Heat Transfer Laboratory, Mechanical Engineering Department, Ben-Gurion University of the Negev, Beer-Sheva, Israel 2004.

22. Kozak Y., Abramzon B., Ziskind G., Experimental and numerical investigation of a hybrid PCM-air heat sink, Appl. Therm. Eng., 59 (1-2), 142-152, 2013.

23. Letan, R., Ziskind G., Thermal design and operation of a portable PCM cooler, Heat Transfer Calculations, in M. Kutz, ed. McGraw-Hill, New York, chapter 39, 2006.

24. Dubovsky V., Ziskind G., Letan R., Analytical model of a PCM air heat exchanger, Appl. Therm. Eng., Cilt 31, 3453-3462, 2011.

25. Ezra M., Kozak Y., Dubovsky V., Ziskind G., Analysis and optimization of melting temperature span for a multiple PCM latent heat thermal energy storage unit, Appl. Therm. Eng., 93, 315-329, 2016.

26. Holman, J.P., Heat Transfer, Ninth Edition, McGrawHill, New York, 2009. 
